\title{
The Role of Computer Design Software in Helping to Analyze The Condition of The Site in The Building Design
}

\author{
Erick Teguh Leksono \\ Arts \& Design Faculty, Interior Design \\ University of Trisakti Jakarta, Indonesia \\ erick.leksono@gmail.com
}

\begin{abstract}
Nowadays, Technology development makes the world move very fast and rapidly changed. It reshapes every aspects in our Life. Most people are using modern technology to do their activity, they have technology devices, such as Computers, Laptops and smartphones, so they can easily get the information that they need in the second count. This circumstances have made the communication easier, we can browse Internet anytime, anywhere, as if our lives are spoiled by this Phenomenon. Undoubtedly, technology is important part of our lives. Architects or designers are challenged to describe their design concept as soon as possible, so their design innovation and problem solution can be applicated and used by the public soon.
\end{abstract}

Keywords: Software, building, Site, Analyze.

\section{INTRODUCTION}

Getting Information and doing Communication easier, one of the positives effect of this condition are increasing our knowledge and by doing our job also become easier. Technology can shapes the future, according to this conference event theme "Empowering Creative Media, Design \& Technology Toward Regional Building", the development of computer software program contributes the convenience methode in design process. It help us, when we want to do the design experiment, we can easily to do many design alternative creatively and our design product will also easily meet the expectation. This condition forces every architect and designer to be able to run such a computer design software.

\section{LITERATURE REVIEWS}

In his book, Site analysis : Diagramming Information for Architectural Design, Edward T. White described the site design process as preliminary phase, which divided into three phases : Research phase, Analysis phase and Synthesis phase. In the research phase, as the user analysis, an architect defines the initial problem, which occur on the site, and can be used as reference on the next analysis phase. There are numerous site elements related to the analysis phase, such as location, surrounding environment context, size, property lines, building setback lines, infrastructure and utilities, circulation of existing pathways (pedestrian, cyclist, vehicle), legal and easement, sensory element (noise, odors, smoke, pollutant), north arrow, climate, wind direction, sun path, slope, significant views, site features, zoning and community restrictions, human culture. The next step, the site elements, that have been analyzed, will be developed on the synthesis phase and deal with site plan schematic design.

To know how well the site plan schematic design functions in relation to our overall design goals, we need visual information performance from our building's site analyzing and it should be simulated, because the simulation is important tool to create a qualitative visual interpretation of what the space on the building site may actually be like.

\section{PROBLEM STATEMENTS}

To keep up with the times that are running so fast, Architects are challenged to do their job and describe their design concept as soon as possible. They are responsible for fast, precise and accurate work. In what ways and assistance, so that they can meet the needs and compensate for such rapid development.

\section{METHODOLOGY}

By using descriptive methode, we try to observe and pay attention how architects do to analyze the condition of the building's site before they design a building. As one description, a few years ago, before the development of computer creative design software technology, if the architects wanted to analyze the site elements, with their stationary, they worked manually and they sketched and calculated the site condition in a spatial dimension one by one in one direction on the paper and it took a long time. In order to conduct site elements availability analysis, they built physical scale model mock-ups to simulate them. Although it can represent any building's site geometry with qualitative and quantitative information, it is not easy to demonstrate the design changes and need to built another model again. It is also difficult to create a model with the appropriate material textures. It tooks more time to simulate the building's site condition with physical model.

After that, computer technology comes to help architects in the analyzing condition of the site elements such as climate, weather, sunlight and design simulation phase in order to provide more design information and get immediately feedback to them, so the design problem that arise, can be fast and easy solved. Many computer softwares have tools to assist in three dimensional modeling, if there are Iterations in design changes, it can be fast to develop and demonstrate.

\section{RESULT OF THE ANALYSIS}

With help from computer technology, site elements such as climate, weather and sunlight can be predicted and simulated everyday, The Temperature from the 
regional part of the earth can be counted appropriately. The environment condition in each geographical zone are not same, tropic, subtropic, temperate and frigid zone on the earth are different, each has its own characteristics. These datas are needed, When architects want to design a building which located in various place in the world. With the help of computer technology, this situation can be cloned and simulated into the computer software and plugged in to creative computer design software. It helps architects and designers in order to realize their creative idea in building and interior design experiment in a short time. It is expected, that their design solution is more precise according to the existing data and the building design result becomes comfortable, when user stay inside the building and give positive influence to the environment surrounding.

\section{DISCUSSION}

Nowadays, with help from internet web mapping service, we can easily find the location of land, that we want to build some or more building onto it. By knowing the global positioning system (GPS) coordinates (latitude $\&$ longitude, that formatted in Degrees, Minutes and Seconds) from our site of land in the map, we can get detailed Information about its geographical regions and site condition, such as satellite imagery, street maps, $360^{\circ}$ panoramic views of streets, real-time traffic conditions, and route planning for traveling by public transportation, bicycle, car or foot.

In some computer design software, the information about climate, weather and sunlight in every zone on the earth is already provided. Through this software, we can easily analyze and observe the behavior of existing climate, weather and sunlight condition for our building design process on the site. By using internet web mapping service, the coordinates latitude and longitude of our land footprint can be detected correctly and fastly. This coordinates data is can be inputed into the creative software design, which already has the information about the climate, weather and sunlight timelines condition from the location, so we can do our building design experiment easily in accordance with the existing condition and get the sustainable design result.

Other than that, by knowing the real - time traffic condition, and route to the location by foot, car, bicycle and public transportation from the web mapping service, our site analizing can be close to the current circumtances and the changes can be predicted and problems arise can be also correctly anticipated. For example, by the site visit, if we have difficult access to the site location, first we can observe the site just from the web map, analyze site elements, collect and compile the data sufficiently. After that we can go to the site shortly and cross checking the result of our site analyzing from the web map. The experiment time becomes shorter, if we compared with the site visit oftenly.

Then, with computer creative design software, we can input colour and texture from building material with many alternatives exploration according to the design theme that we want to express and according to the existing condition and expectation. It is easier, to mix and match building design elements, so the building appearance is fit with its function, then, they become harmonious in unity

\section{ACKNOWLEDGMENT}

This technology gives architects and designers the strength to spread their design horizon, the computer design software program plays a big role in creative design business in the future.If the architects and designers, before launch their design product result, want to simulate their design, with helps from the software, the mock ups can be visualized and simulated without spend money and time, although some software can be costly. The design documents and the result, that they have, can be saved and documented inside the computer very well, so they don't need such a big store to keep all documents that they have. If not for computer, where would the million of documents be saved

\section{CONCLUSION}

Working with the software, make the design process that took hours to complete, can be created as soon as possible. The complex design things, which have many discussion, can be helped to find out the solution and the creative design form can be also easy imagined and visualized.

\section{REFERENCES}

[1] T.WHite, Edward (1983). Site Analysis: Diagramming Information for Architectural Design Florida: Architectural media

[2] Seventwave (2018). Daylighting analysis. Retrieved on August 07,2018, from https://www.sevenwave.org/daylighting/analysis.

[3] Hirsch, Bill.(2018). About Home Design. Retrieved on August 06, 2018, from www.about-homedesign.com/building-sites.html

[4] News from Google ( November 28, 2007).Google Announces Launch of Google Maps for Mobile With "My Location" Technology.

Retrieved on August 19, 2018, from http://googlepress.blogspot.com/2007/11/googleannounces-launchof-google-maps_28.html

[5] Google Maps Help (2018).Get directions and show routes. Retrieved on August 19, 2018, from https://support.google.com/maps/answer/144339 